\title{
Penehyclidine hydrochloride alleviates lipopolysaccharide-induced acute respiratory distress syndrome in cells via regulating autophagy-related pathway
}

\author{
XIAOPENG WANG, FEN LIU, MIN XU and LIANGXIA WU \\ Department of Pediatrics, Shanghai Jiaotong University Affiliated Sixth People's Hospital, Shanghai 200233, P.R. China
}

Received July 27, 2019; Accepted April 30, 2020

DOI: $10.3892 / \mathrm{mmr} .2020 .11739$

\begin{abstract}
Acute progressive hypoxic respiratory failure caused by various predisposing factors is known as acute respiratory distress syndrome (ARDS). Although penehyclidine hydrochloride (PHC), an anticholinergic drug, is widely applied in clinical practice, the specific mechanisms underlying PHC in the treatment of ARDS are not completely understood. In the present study, BEAS-2B cells were treated with $10 \mathrm{ng} / \mathrm{ml}$ lipopolysaccharide (LPS) to establish an ARDS cell model and a rat model of acute lung injury (ALI). The influences of PHC and/or autophagy inhibitor (3-methyladenine (3-MA)) on the morphology, autophagy, proliferation and apoptosis of cells and tissues were evaluated using hematoxylin and eosin staining, Cell Counting Kit-8 assays, Hoechst staining, TUNEL staining, flow cytometry, immunofluorescence assays, ELISAs and scanning electron microscopy. The expression levels of apoptosis- and autophagy-related proteins were measured via western blotting. The results indicated that PHC enhanced proliferation and autophagy, and decreased apoptosis and the inflammatory response in LPS-induced BEAS-2B cells and ALI model rats. In addition, 3-MA reversed the effects of PHC on proliferation, inflammation, apoptosis and autophagy in LPS-induced BEAS-2B cells. Therefore, the present study suggested that PHC demonstrated a protective effect in LPS-induced ARDS by regulating an autophagy-related pathway.
\end{abstract}

Correspondence to: Dr Liangxia Wu, Department of Pediatrics, Shanghai Jiaotong University Affiliated Sixth People's Hospital, 600 Yishan Road, Xuhui, Shanghai 200233, P.R. China

E-mail: wuliangxia6@126.com

Abbreviations: ARDS, Acute respiratory distress syndrome; PHC, penehyclidine hydrochloride; LPS, lipopolysaccharide; 3-MA, 3-methyladenine; TEM, transmission electron microscopy; Rapa, rapamycin; IF, immunofluorescence

Key words: penehyclidine hydrochloride, autophagy, acute respiratory distress syndrome, lipopolysaccharide, apoptosis

\section{Introduction}

Acute lung injury (ALI) causes high morbidity and when aggravated further, develops into acute respiratory distress syndrome (ARDS) with a fatality rate $\leq 40 \%$ worldwide (1). Pulmonary and extrapulmonary factors are responsible for causing ARDS (2). The common pathophysiologic features of ARDS are injury to the pulmonary alveoli epithelial cells and pulmonary capillaries, with refractory hypoxemia being a conspicuous feature (3). Bluish skin coloration, shortness of breath and rapid breathing are also prominent symptoms of ARDS (4). The high mortality of ARDS has received increasing attention, with several studies indicating that ARDS may be closely associated with conditions such as pancreatitis (5,6), sepsis (7), aspiration (8), pneumonia (9) and trauma (10). ARDS pathogenesis comprises diffuse cell damage, including diffuse cell injury, pulmonary microballoon barrier formation, surfactant dysfunction, immune system activation and coagulation regulation dysfunction $(11,12)$.

Lipopolysaccharide (LPS) is found on the cytoderm of Gram-negative bacteria and significantly contributes to pulmonary infection and sepsis by protecting the bacterial cell wall $(13,14)$. As indicated by several studies, LPS is a common pathogenic factor of ALI/ARDS (15-17); therefore, it can be used to establish ARDS cell models.

Penehyclidine hydrochloride (PHC) is an anticholinergic drug that is widely used in the clinic for organophosphorus poisoning, visceral smooth muscle spasms and as a reversal agent for anesthesia (18). PHC may participate in overcoming microcirculation disorders and aid in organ protection (19). PHC is beneficial in pharmacology compared with other anticholinergic agents, including atropine and scopolamine (20). In addition, PHC possesses anti-inflammatory, antioxidative and antiapoptotic features, which serve protective effects in various organs such as the lungs (21), brain (22) and heart (23). In ARDS, excessive release of acetylcholine in the body results in acute pulmonary microcirculation disorder, leading to pulmonary microcirculation spasm (24). Thus, by preventing pulmonary permeability via decreasing the damage of ARDS to the microvascular barrier, PHC can improve the pulmonary inflammatory response and ventilation function in ARDS (25). The protective role of PHC in ARDS has been reported in several studies $(26,27)$; however, the mechanisms 
underlying the effects of PHC on autophagy have not been previously reported.

The present study aimed to investigate the effects of PHC on cell activities, such as proliferation, inflammation, apoptosis and autophagy, in LPS-induced BEAS-2B cells. The effect of PHC on the expression levels of apoptosis- and autophagy-related proteins was assessed, and the reversal effect of autophagy inhibitor (3-methyladenine (3-MA)) on PHC in ARDS was also investigated.

\section{Materials and methods}

Cell culture. Lung alveolar epithelial cells (BEAS-2B; American Type Culture Collection) were cultured in DMEM medium (cat. no. 31600-026; Gibco; Thermo Fisher Scientific, Inc.) with $10 \%$ fetal bovine serum (FBS; cat. no. SH30071.03; HyClone; GE Healthcare Life Sciences) and penicillin/streptomycin (cat.no. 10378-016; Invitrogen; Thermo Fisher Scientific, Inc.). Cells were cultured in an incubator with $5 \% \mathrm{CO}_{2}$ at $37^{\circ} \mathrm{C}$. Cells in the logarithmic phase were used for subsequent experiments.

Grouping and modeling. To establish a cell model of ARDS, BEAS-2B cells in the logarithmic stage of growth were treated with $10 \mathrm{ng} / \mathrm{ml}$ LPS (Sigma-Aldrich; Merck KGaA). Following incubation for $12 \mathrm{~h}$ at $37^{\circ} \mathrm{C}$, the ARDS cell model was treated with $0.01,0.05$ and $1.0 \mu \mathrm{M}$ PHC (cat. no. BP0704-YTX; Beijing Baiaolaibo Technology Co., Ltd.) for $1 \mathrm{~h}$ at $37^{\circ} \mathrm{C}$. And the ARDS cells in the control group were also given an equal amount of double distilled water. ARDS model cells were divided into the following groups: i) Control (normal saline); ii) LPS; iii) LPS-PHC-low concentration (LPS and $0.01 \mu \mathrm{M}$ PHC); iv) LPS-PHC-medium concentration (LPS and $0.05 \mu \mathrm{M} \mathrm{PHC}$ ); and v) LPS-PHC-high concentration $(1.0 \mu \mathrm{M})$. Alternatively, following treatment with $0.05 \mu \mathrm{M}$ PHC, LPS-induced BEAS-2B cells were treated with $100 \mathrm{nM}$ autophagy agonist rapamycin (Rapa; cat. no. IMT1001-100MG; Gene Operation) or $10 \mathrm{mM}$ autophagy inhibitor (3-MA; cat. no. S2767-1; Selleck Chemicals).

Western blot analysis. BEAS-2B cells from each group were lysed using RIPA Lysis buffer (Beyotime Institute of Biotechnology) on ice. The BCA protein assay kit (Pierce; Thermo Fisher Scientific, Inc.) was used to quantify the total protein concentration. Protein samples $(30 \mu \mathrm{g}$ per lane) were separated via 10\% SDS-PAGE (Beijing Solarbio Science \& Technology Co., Ltd.) and transferred to PVDF membranes (Sigma-Aldrich; Merck KGaA). The membranes were blocked with 5\% non-fat dry milk (cat. no. 198-10605; Wako Chemicals $\mathrm{GmbH}$ ) at room temperature for $1.5 \mathrm{~h}$ to block nonspecific protein binding sites. Subsequently, the membranes were incubated at $4^{\circ} \mathrm{C}$ overnight with primary antibodies targeted against: Bax (cat. no. SAB2108447; 1:1,000; Sigma-Aldrich; Merck KGaA), Bcl-2 (cat. no. SAB5500014; 1:1,000; Sigma-Aldrich; Merck KGaA), caspase-3 (cat. no. ZRB1221; 1:1,000; Sigma-Aldrich; Merck KGaA), Beclin-1 (cat. no. ab62557; 1:1,000; Abcam), light chain 3 (LC3B; cat. no. ab168831; 1:1,000, Abcam), p62 (cat. no. ab91526; 1:1,000; Abcam) and GAPDH (cat. no. G5262; 1:100; Sigma-Aldrich; Merck KGaA). Following primary incubation, the membranes were incubated with goat anti-rabbit IgG H\&L (cat. no. ab6721; 1:5,000; Abcam) and goat anti-mouse IgG H\&L (cat. no. ab205719; 1:5,000; Abcam) secondary antibodies at room temperature for $1 \mathrm{~h}$. Protein bands were visualized using an enhanced chemiluminescence kit (cat. no. 32106; Invitrogen; Thermo Fisher Scientific, Inc.). Protein expression was semi-quantified using Image-pro Plus analysis software (version 6.0; Media Cybernetics, Inc.) with GAPDH as the loading control.

Immunofluorescence (IF) assay. BEAS-2B cells $\left(5 \times 10^{4}\right.$ cells $\left./ \mathrm{ml}\right)$ from each group were harvested and mounted on coverslips. Cells were fixed using $4 \%$ paraformaldehyde (cat. no. P61481; Sigma Aldrich; Merck KGaA) at room temperature for $10 \mathrm{~min}$. After washing with PBS, permeabilization was conducted with $0.3 \%$ Triton X-100 (Sigma-Aldrich; Merck $\mathrm{KGaA}$ ) at room temperature for $10 \mathrm{~min}$. Following rinsing with PBS, cells were blocked using $5 \%$ bovine serum albumin (cat. no. A7906; Sigma-Aldrich; Merck KGaA) at room temperature for $2 \mathrm{~h}$ and incubated with an anti-LC3B primary antibody (cat. no. ab51520; 1:500; Abcam) at $4^{\circ} \mathrm{C}$ overnight. Cells were subsequently washed and incubated with a secondary fluorescein-conjugated antibody (cat. no. 4414; 1:200; Cell Signaling Technology, Inc.) at room temperature for $1 \mathrm{~h}$. Cells were washed with PBS and stained with DAPI (cat. no. D9542; Sigma-Aldrich; Merck KGaA) at room temperature for $5 \mathrm{~min}$. Stained cells were visualized using an SZX12 fluorescent microscope (Olympus Corporation) at x200 magnification.

Cell counting Kit-8 (CKK-8) assay. BEAS-2B cells were seeded $\left(3.0 \times 10^{3}\right.$ cells/well) into 96-well plates. Cells were treated with varying concentrations of PHC, $100 \mathrm{nM}$ Rapa or $10 \mathrm{mM} 3-\mathrm{MA}$ in an incubator at $37^{\circ} \mathrm{C}$ with $5 \% \mathrm{CO}_{2}$ for 24,48 or $72 \mathrm{~h}$. Subsequently, $10 \mu \mathrm{l} \mathrm{CCK}-8$ solution $(5 \mathrm{mg} / \mathrm{ml}$; Dojindo Molecular Technologies, Inc.) was added to each well. After incubation at $37^{\circ} \mathrm{C}$ for $2 \mathrm{~h}$, the absorbance of each well was measured at a wavelength of $450 \mathrm{~nm}$ using a microplate reader.

ELISA. As previously described (28), The concentrations of factors in the culture medium of each group, such as interferon (IFN)- $\gamma$, tumor necrosis factor (TNF)- $\alpha$, interleukin (IL)- $1 \beta$ and IL-6, were measured via ELISA. The following ELISA kits were used: IFN- $\gamma$ (cat. no. ab46048; Abcam), TNF- $\alpha$ (cat. no. E-EL-H0109c; Elabscience), IL-1 $\beta$ (cat. no. E-EL-H0149c; Elabscience) and IL-6 (cat. no. E-EL-H0102c; Elabscience). Nitric oxide (NO) levels were assessed using a Nitrite Colorimetric kit (cat. no. E-BC-K070-S; Elabscience).

Flow cytometry analysis. To measure the early + late apoptosis, the Annexin V/FITC kit (cat. no. PHN1008; Invitrogen; Thermo Fisher Scientific, Inc.) was used. Briefly, cells were collected at a density of $5.0 \times 10^{5}$ cells $/ \mathrm{ml}$ and resuspended in PBS. Subsequently, cells were transferred to flow tubes and incubated with $5 \mu \mathrm{l}$ Annexin V/FITC at room temperature for 5 min and then rinsed with ice-cold PBS. Fluorescence intensity was determined using a FACScan flow cytometer (BD Biosciences), and the data was analyzed using Cell Quest 3.1 software (BD Biosciences). 
Hoechst staining. BEAS-2B cells were harvested and the cell density was calibrated to $6 \times 10^{4}$ cells $/ \mathrm{ml}$ and cultured in 6-well plates at $37^{\circ} \mathrm{C}$ with $5 \% \mathrm{CO}_{2}$ for $24 \mathrm{~h}$. Subsequently, cells were washed with PBS and fixed with $4 \%$ paraformaldehyde (cat. no. abx082483; Abbexa Ltd.) at room temperature for $20 \mathrm{~min}$. Cells were rinsed with PBS and stained using $1 \mathrm{ml}$ Hoechst 33342 (20 $\mu \mathrm{g} / \mathrm{ml}$; Invitrogen; Thermo Fisher Scientific, Inc.) at room temperature for $10 \mathrm{~min}$. Stained cells were observed using an A1R/A1 confocal laser scanning microscope (Nikon Corporation) at x200 magnification.

Transmission electron microscopy (TEM). Cell autophagy was assessed by TEM. BEAS-2B cells ( $5 \times 10^{5}$ cells) were resuspended in PBS and fixed with 2.5\% glutaraldehyde (cat. no. G7776; Sigma-Aldrich; Merck KGaA) for $2 \mathrm{~h}$ at $4^{\circ} \mathrm{C}$. Subsequently, cells were rinsed with PBS three times, and treated with $1 \%$ uranyl acetate (cat. no. 0509-25G; Amresco, LLC) at room temperature for 20 mins. Cells were dehydrated using 50, 70, 80 and $90 \%$ acetone (cat. no. 650501; Sigma-Aldrich; Merck KGaA). The cells were embedded with the epoxy resin mixture at room temperature for 20 mins. The prepared cells were observed under a H-7650 transmission electron microscope (Hitachi High-Technologies Corporation) at $\mathrm{x} 40,000$ magnification to study the morphology of BEAS-2B cells.

Animal experiments. Male SD rats ( $\mathrm{n}=40$; age, 8 weeks; weight, 200-250 g; SPF grade) purchased from the Experimental Animal Center of Shanghai Jiaotong University, China were randomly divided into five groups ( $\mathrm{n}=8$ per group). Rats were intraperitoneally injected with $5 \mathrm{mg} / \mathrm{kg}$ LPS (cat. no. L8880; Beijing Solarbio Science \& Technology Co., Ltd.) or an equal volume of normal saline (control). Prior to the experiment, all rats were kept adaptively for one week. Rats were housed at $18-22^{\circ} \mathrm{C}, 50-60 \%$ humidity, with a $12 \mathrm{~h}$ light/dark cycle and had free access to food and water. The present study was approved by the Ethics Committee of the Shanghai Jiaotong University Affiliated Sixth People's Hospital. Rats were intraperitoneally injected with $0.3,1.0$ or $3.0 \mathrm{mg} / \mathrm{kg}$ PHC $30 \mathrm{~min}$ before LPS injection. After treatment with LPS for $24 \mathrm{~h}$, the rats were sacrificed using a Quietek $\mathrm{CO}_{2}$ Delivery Systems (HEAD Beijing Biotechnology Co., Ltd.). Briefly, $100 \% \mathrm{CO}_{2}$ was delivered from a purified compressed air cylinder with a special valve (Guangzhou Yigas Gases, Co., Ltd.) to the cage at a volume displacement rate of $30 \%$ per $\min (\sim 5 \mathrm{l} / \mathrm{min})$ using a flowmeter (Hua Yun Meter Co., Ltd.). The lung tissues of each group were fixed with $4 \%$ paraformaldehyde at room temperature for $20 \mathrm{~min}$.

Hematoxylin and eosin $(H \& E)$ staining. The lung tissues were dehydrated using a graded series $(100,95,80$ and $75 \%)$ of ethanol and cleared using dimethylbenzene. Following paraffin embedding, the tissues were cut into $4-\mu \mathrm{m}$ sections. The sections were heated, dewaxed, hydrated and stained using the hematoxylin and eosin staining kit (cat. no. C0105; Beyotime Institute of Biotechnology) according to the manufacturer's instructions. Subsequently, the sections were placed in $1 \%$ hydrochloric acid alcohol for $30 \mathrm{sec}$. Following dehydration, clearing and mounting, five random fields of the stained sections were observed under a CKX41 light microscope (Olympus Corporation) at x200 magnification.
TUNEL staining. After the tissue sections had been dewaxed with dimethylbenzene, hydrated with 100,90 and 70\% ethanol and washed with PBS, the tissue sections were incubated with $20 \mu \mathrm{g} / \mathrm{ml}$ protease $\mathrm{K}$ at $37^{\circ} \mathrm{C}$ for 15 mins to remove the tissue proteins. Subsequently, the sections were treated with $100 \mu 1$ TUNEL reaction mixture (cat. no. C1086; Beyotime Institute of Biotechnology) at $37^{\circ} \mathrm{C}$ for $1 \mathrm{~h}$, followed by incubation with $100 \mu 1$ DNase at room temperature for $5 \mathrm{~min}$. Following washing with PBS, the sections were treated with $3 \mathrm{ml} / 1 \mathrm{H}_{2} \mathrm{O}_{2}$ for $5 \mathrm{~min}$ at room temperature to block endogenous peroxidase. Subsequently, $100 \mu 1$ streptavidin-labeled HRP (1:50) was added to the sections at room temperature for $30 \mathrm{~min}$. Following washing with PBS, the sections were treated with $100 \mu \mathrm{l}$ DAB for at room temperature $10 \mathrm{~min}$ in the dark. The sections were re-stained with hematoxylin at room temperature for $3 \mathrm{~min}$, dehydrated with gradient alcohol (80, 90 and 100\%), cleared with dimethylbenzene and sealed with neutral balsam. Apoptotic cells were observed and the images from five random fields were captured using an IX73 fluorescence microscope (Olympus Corporation) at x200 magnification.

Statistical analysis. Statistical analyses were performed using SPSS software (version 19.0; IBM Corp.). All experiments were performed at least three times. Data are presented as the mean \pm SD. The data between two groups were analyzed using the unpaired Student's t-test, and the data between the multiple groups were analyzed by a one-way ANOVA followed by Tukey's post hoc test. $\mathrm{P}<0.05$ was considered to indicate a statistically significant difference.

\section{Results}

PHC accelerates proliferation and inhibits apoptosis in $L P S$-induced BEAS-2B cells. First, the effect of PHC on ARDS proliferation and apoptosis was investigated. As indicated in Fig. 1A, LPS significantly reduced BEAS-2B cell proliferation compared with the control group, which was rescued by PHC in a dose-dependent manner. Hoechst staining and flow cytometry demonstrated that the rate of cell apoptosis was increased in the LPS group compared with the control group; whereas PHC treatment inhibited LPS-induced BEAS-2B cell apoptosis, with increasing PHC concentrations significantly decreasing the rate of LPS-induced apoptosis (Fig. 1B and C). Based on the aforementioned findings, it was hypothesized that PHC could inhibit LPS-induced apoptosis in a dose-dependent manner. Western blotting was performed to verify the expression levels of apoptosis-related proteins (Bax, caspase-3 and Bcl-2). As demonstrated in Fig. 1D, the expression levels of proapoptosis genes (Bax and caspase-3) were significantly increased in the LPS group compared with the control group. LPS-induced Bax and caspase-3 expression levels were inhibited by PHC treatment in a dose-dependent manner. By contrast, antiapoptotic factor Bcl-2 expression was significantly decreased in the LPS group compared with the control group, and PHC treatment significantly increased $\mathrm{Bcl}-2$ expression in a dose-dependent manner compared with the LPS group. Therefore, the results indicated that PHC inhibited LPS-induced apoptosis. 

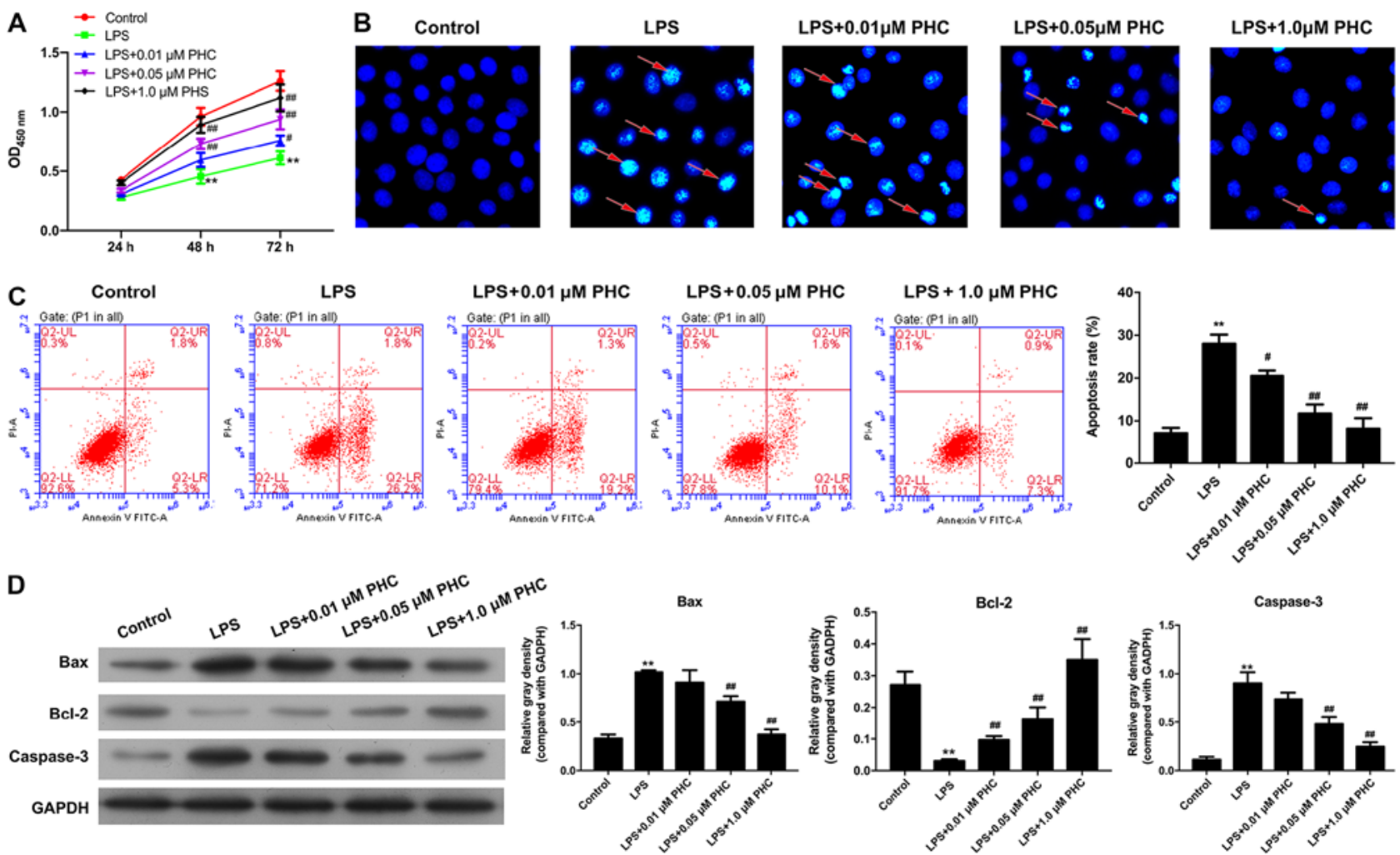

Figure 1. PHC accelerates proliferation and inhibits apoptosis in LPS-induced BEAS-2B cells. An ARDS cell model was established by treating BEAS-2B cells with $10 \mathrm{ng} / \mathrm{ml}$ LPS and different concentrations of PHC. (A) The effects of PHC on cell proliferation were determined by performing the Cell Counting Kit-8 assay. (B) Hoechst staining was used to analyze BEAS-2B cell apoptosis. Red arrows indicate apoptotic cells. magnification, x200. (C) Flow cytometry analysis was performed to examine the effects of PHC on LPS-induced BEAS-2B cell apoptosis and the rate of apoptosis was calculated. (D) Bax, Bcl-2 and caspase-3 expression levels were determined by western blotting and semi-quantified. ${ }^{* *} \mathrm{P}<0.01$ vs. control group; ${ }^{*} \mathrm{P}<0.05,{ }^{\# \#} \mathrm{P}<0.01$ vs. LPS group. PHC, penehyclidine hydrochloride; LPS, lipopolysaccharide; ARDS, acute respiratory distress syndrome; OD, optical density.
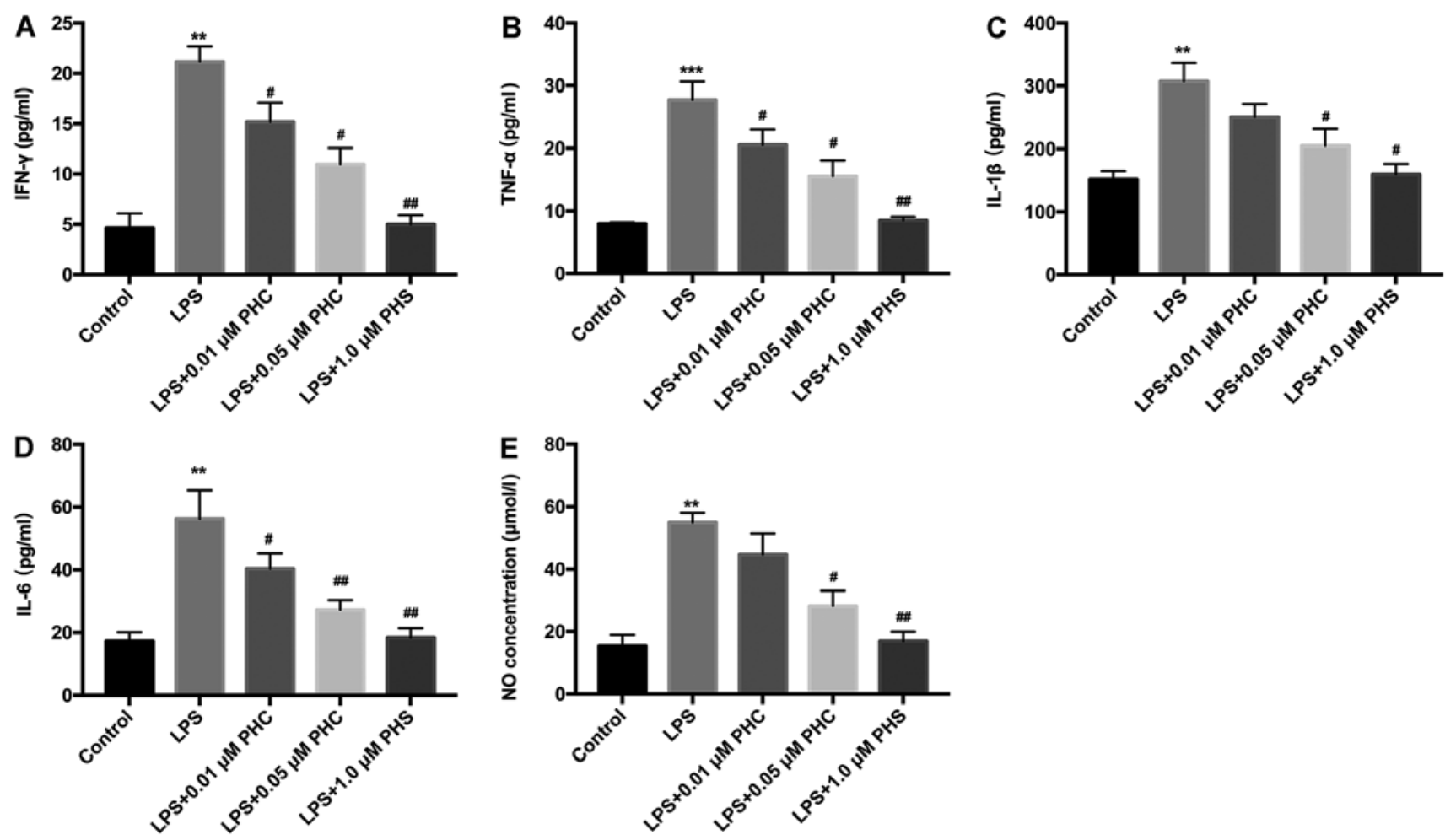

Figure 2. PHC downregulates ARDS injury-related markers in LPS-induced BEAS-2B cells. Following PHC treatment, the levels of (A) IFN- $\gamma$, (B) TNF- $\alpha$, (C) IL-1 $\beta$, (D) IL-6 and (E) NO were analyzed by ELISA in the medium of the LPS-induced BEAS-2B cells. ${ }^{* *} \mathrm{P}<0.01$ and ${ }^{* * *} \mathrm{P}<0.001$ vs. control group; ${ }^{\#} \mathrm{P}<0.05$ and ${ }^{\# \#} \mathrm{P}<0.01$ vs. LPS group. PHC, penehyclidine hydrochloride; ARDS, acute respiratory distress syndrome; LPS, lipopolysaccharide; IFN, interferon; TNF, tumor necrosis factor; IL, interleukin; NO, nitric oxide. 
A Control

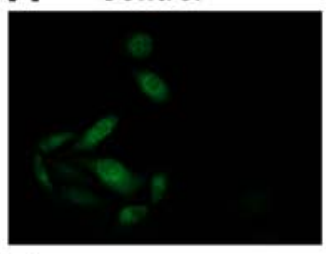

B Control

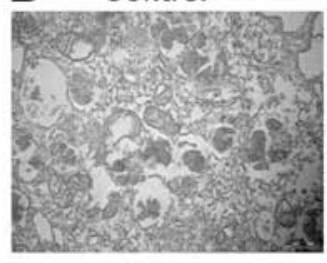

LPS

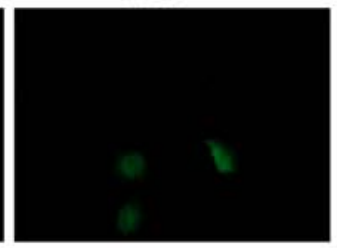

LPS

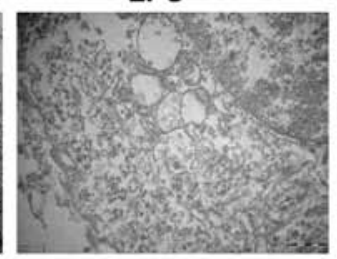

LPS $+0.01 \mu \mathrm{M}$ PHC

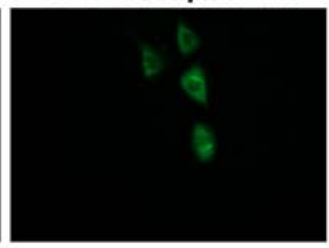

LPS $+0.01 \mu \mathrm{M}$ PHC

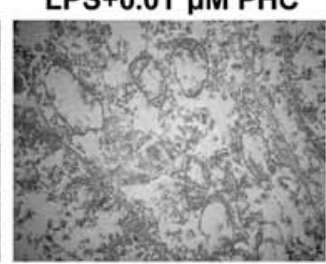

LPS $+0.05 \mu \mathrm{M}$ PHC

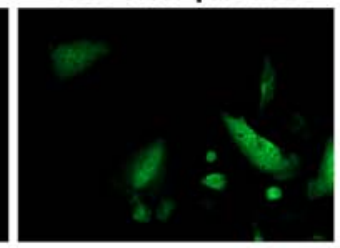

LPS $+0.05 \mu \mathrm{M}$ PHC

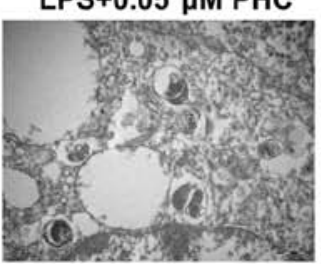

LPS $+1.0 \mu \mathrm{M}$ PHC

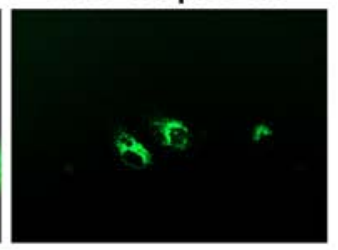

LPS+1.0 $\mu \mathrm{M}$ PHC

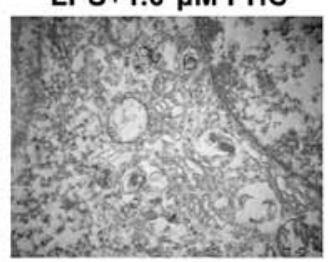

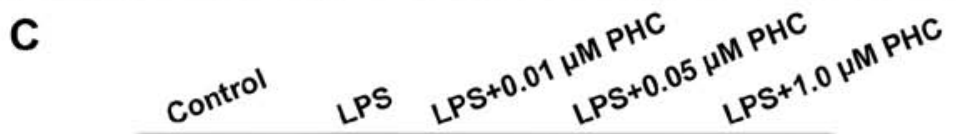

LC3B

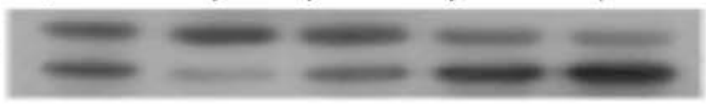

p62

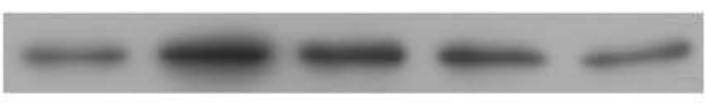

Beclin-1

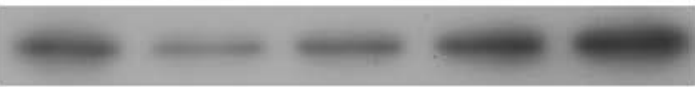

GAPDH

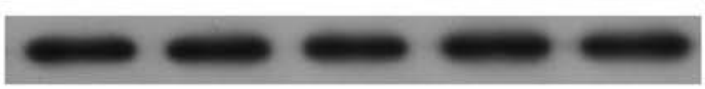

D

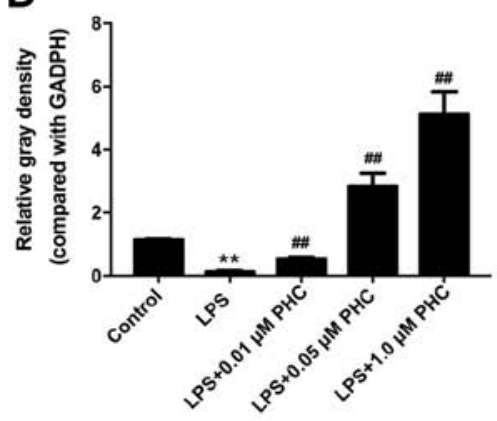

p62

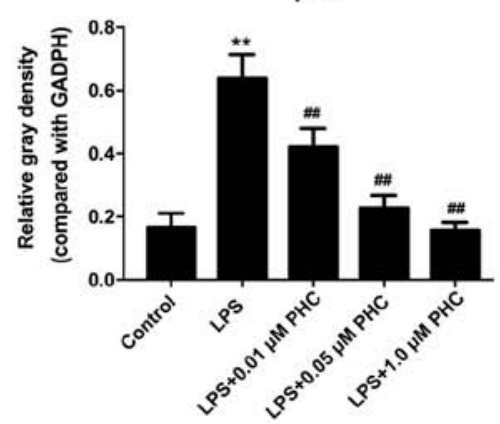

Beclin-1

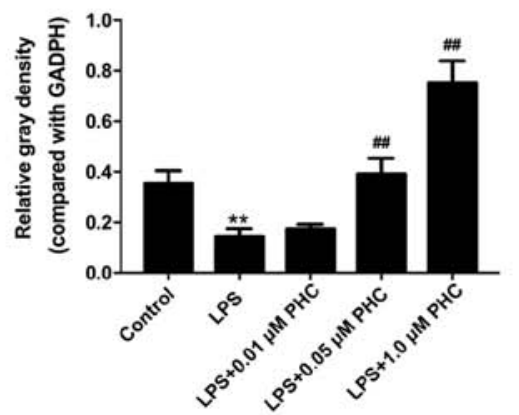

Figure 3. PHC facilitates autophagy in LPS-induced BEAS-2B cells. BEAS-2B cells were treated with $10 \mathrm{ng} / \mathrm{ml}$ LPS and different concentrations of PHC. (A) LC3B expression was measured by performing immunofluorescence assays. Green indicates LC3B expression and blue (DAPI) indicates the nuclei (magnification, x200). (B) Transmission electron microscopy was conducted to observe autophagosomes at x40,000 magnification. LC3B, p62 and Beclin-1 expression levels were (C) determined by western blotting and (D) semi-quantified. ${ }^{* *} \mathrm{P}<0.01$ vs. control group; ${ }^{\# \#} \mathrm{P}<0.01$ vs. LPS group. PHC, penehyclidine hydrochloride; LPS, lipopolysaccharide; LC3B, light chain 3.

PHC inhibits inflammatory mediators in LPS-induced $B E A S-2 B$ cells. The effect of PHC-induced ARDS injury was further investigated. As shown in Fig. 2, the levels of IFN- $\gamma$, TNF- $\alpha$, IL-1 $\beta$, IL-6 and NO were significantly elevated in the LPS group compared with the control group, whereas PHC treatment significantly reduced LPS-mediated effects in BEAS-2B cells. Thus, PHC attenuated the LPS-induced inflammatory response in BEAS-2B cells.

PHC facilitates autophagy in LPS-induced BEAS-2B cells. IF assays and TEM observations were conducted to study the effect of PHC on LPS autophagy. The IF assay revealed weaker fluorescence intensity in the LPS group compared with the control group, indicating lower levels of autophagy in the model group. The fluorescence intensity was enhanced by PHC treatment in a concentration-dependent (Fig. 3A). The number of autophagosomes was decreased in the LPS group compared with the control group, and PHC treatment ameliorated the LPS-induced reduction in autophagosomes, with the number of autophagosomes increasing gradually with increasing PHC concentrations (Fig. 3B). Beclin-1 and LC3B expression levels were significantly decreased, and p62 expression levels were significantly increased in the LPS group compared with the control group. LPS-induced alterations to the expression levels of LC3B, p62 and Beclin-1 were reversed by PHC in a dose-dependent manner (Fig. 3C and D).

3-MA reverses the effects of PHC on LPS-induced BEAS- $2 B$ cell proliferation and apoptosis. Subsequently, the influence of PHC on LPS-induced BEAS-2B cell proliferation and 

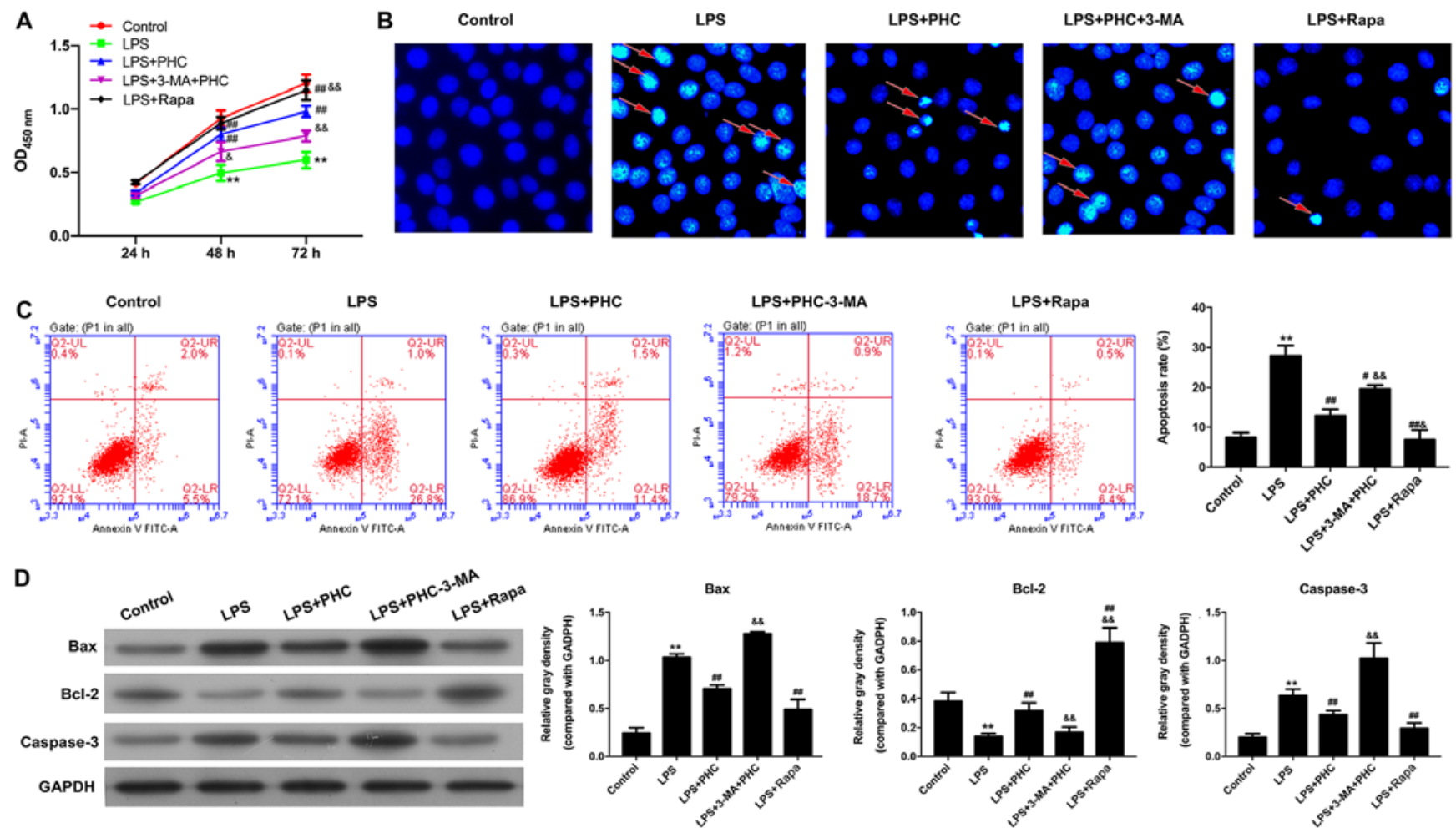

Figure 4. 3-MA reverses the effects of PHC on LPS-induced BEAS-2B cell proliferation and apoptosis. Following treatment with $10 \mathrm{ng} / \mathrm{ml}$ LPS, BEAS-2B cells were treated with $0.05 \mu \mathrm{M}$ PHC, $100 \mathrm{nM}$ Rapa or $10 \mathrm{mM}$ 3-MA. (A) Cell proliferation was examined by performing the Cell Counting Kit-8 assay. (B) Apoptosis was assessed via Hoechst staining. Red arrows indicate apoptotic cells. magnification, x200. (C) Flow cytometry analysis was conducted to evaluate the effects of PHC, Rapa and 3-MA on LPS-induced BEAS-2B cell apoptosis and the rate of apoptosis was calculated. (D) Bax, Bcl-2 and caspase-3 expression levels were measured by western blotting and semi-quantified. ${ }^{* *} \mathrm{P}<0.01 \mathrm{vs.}$. control group; ${ }^{\#} \mathrm{P}<0.01 \mathrm{vs}$. LPS group; \&\& $\mathrm{P}<0.01 \mathrm{vs}$. LPS $+\mathrm{PHC}$ group. 3-MA, 3-methyladenine; PHC, penehyclidine hydrochloride; LPS, lipopolysaccharide; Rapa, rapamycin.
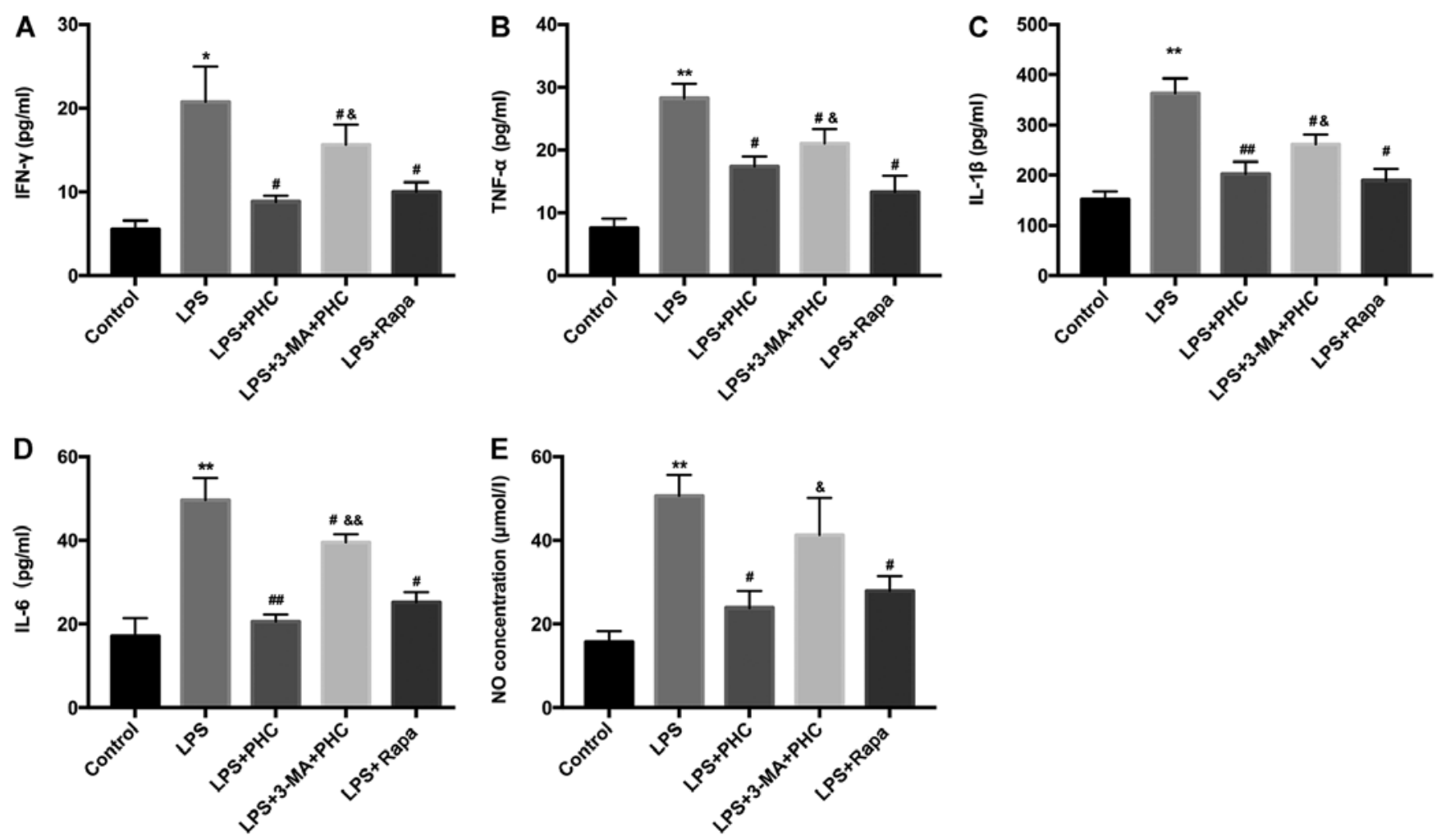

Figure 5. PHC weakens ARDS damage by regulating the autophagy pathway. LPS-induced BEAS-2B cells were treated with PHC, Rapa or 3-MA. ELISAs were performed to analyze alterations to (A) IFN- $\gamma$, (B) TNF- $\alpha$, (C) IL-1 $\beta$, (D) IL-6 and (E) NO levels. " $\mathrm{P}<0.05$ and ${ }^{* *} \mathrm{P}<0.01$ vs. control group; ${ }^{*} \mathrm{P}<0.05$ and ${ }^{\# \#} \mathrm{P}<0.01$ vs. LPS group; ${ }^{\&} \mathrm{P}<0.05$ and ${ }^{\&} \& \mathrm{P}<0.01$ vs. LPS + PHC group. PHC, penehyclidine hydrochloride; ARDS, acute respiratory distress syndrome; LPS, lipopolysaccharide; Rapa, rapamycin; IFN, interferon; TNF, tumor necrosis factor; IL, interleukin; NO, nitric oxide. 

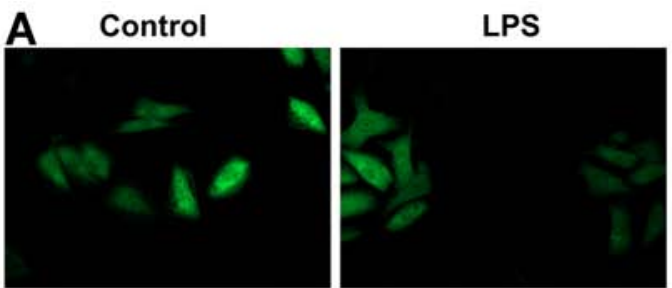

B Control

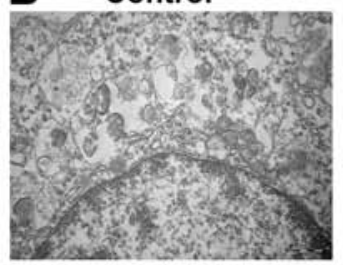

LPS

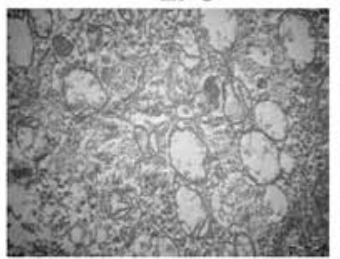

C

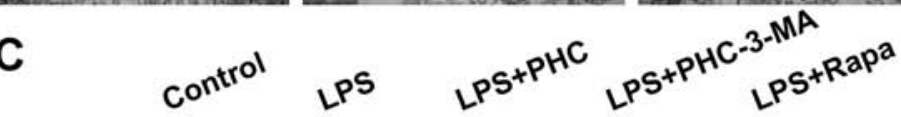

LC3B

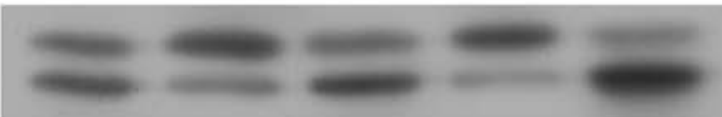

p62

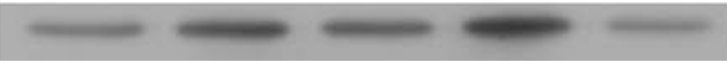

Beclin-1

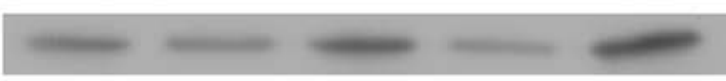

GAPDH 20
D

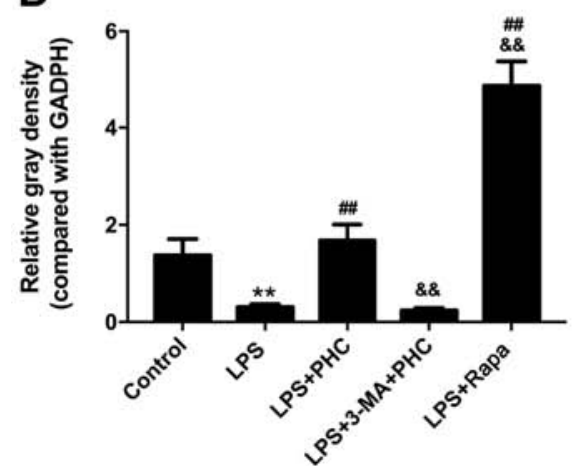

p62

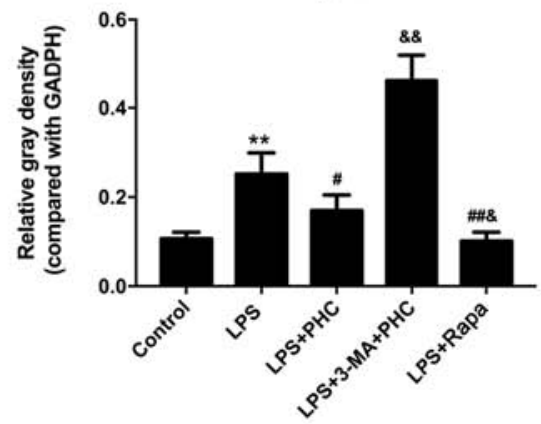

Beclin-1

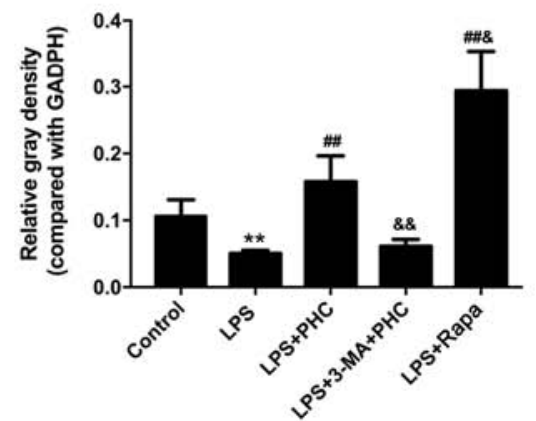

Figure 6. 3-MA reverses the effects of PHC on LPS-induced BEAS-2B cell autophagy. BEAS-2B cells were treated with $0.05 \mu \mathrm{M}$ PHC, $100 \mathrm{nM}$ Rapa or $10 \mathrm{mM}$ 3-MA after treatment with $10 \mathrm{ng} / \mathrm{ml}$ LPS. (A) Immunofluorescence assays were conducted to assess LC3B expression. Green indicates LC3B expression and blue (DAPI) indicates the nuclei (magnification, $x 200$ ). (B) Autophagosomes were observed using a transmission electron microscope at $x 40,000$ magnification. LC3B, p62 and Beclin-1 expression levels were (C) determined by western blotting and (D) semi-quantified. ${ }^{* *} \mathrm{P}<0.01$ vs. control group; ${ }^{*} \mathrm{P}<0.05$ and ${ }^{\# \#} \mathrm{P}<0.01$ vs. LPS group; ${ }^{\&} \mathrm{P}<0.05$ and ${ }^{\& \&} \mathrm{P}<0.01$ vs. LPS + PHC group. 3-MA, 3-methyladenine; PHC, penehyclidine hydrochloride; LPS, lipopolysaccharide; Rapa, rapamycin; LC3, light chain 3.

apoptosis was further investigated. The CCK-8 assay results indicated that PHC reversed the inhibitory effect of LPS treatment on BEAS-2B cell proliferation, whereas 3-MA attenuated the effects of PHC on LPS-treated BEAS-2B cell proliferation (Fig. 4A). In addition, RAPA also enhanced the proliferation of LPS-induced BEAS-2B cells (Fig. 4A). PHC significantly suppressed LPS-induced BEAS-2B cell apoptosis, whereas the 3-MA reversed PHC-mediated apoptosis suppression. The Rapa also significantly inhibited LPS-induced BEAS-2B cell apoptosis (Fig. 4B and C). PHC in combination with 3-MA significantly upregulated the expression levels of proapoptosis genes (Bax and caspase-3) and downregulated antiapoptotic factor Bcl-2 expression compared with PHC alone. Additionally,
Rapa treatment also significantly reduced Bax and caspase-3 expression levels, and significantly increased Bcl-2 expression levels in LPS-treated BEAS-2B cells compared with the LPS group (Fig. 4D).

PHC weakens the inflammatory state by regulating the autophagy pathway in BEAS-2B cells. Whether the effect of PHC on ARDS damage was related to autophagy-related pathways was further investigated. In accordance with the aforementioned results, 3-MA reversed PHC-mediated inhibition of IFN- $\gamma$, TNF- $\alpha$, IL-1 $\beta$, IL- 6 and NO levels in LPS-treated BEAS-2B cells, which suggested that PHC decreased inflammation by regulating the autophagy pathway (Fig. 5). 


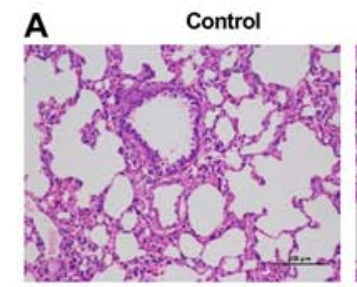

B

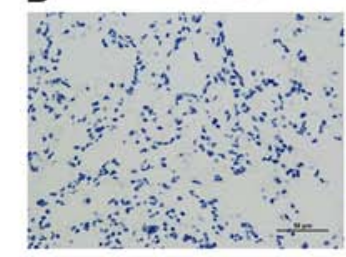

C
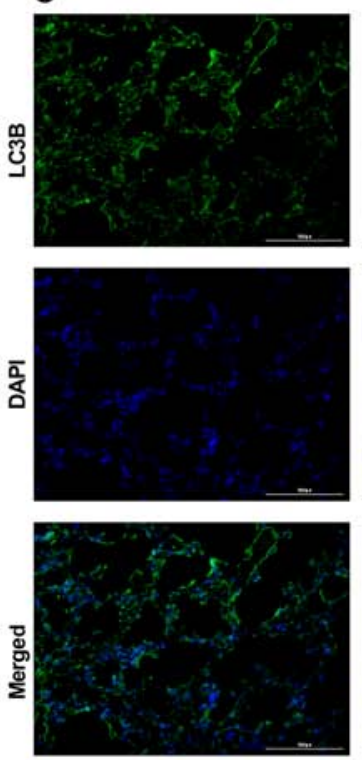

LPS

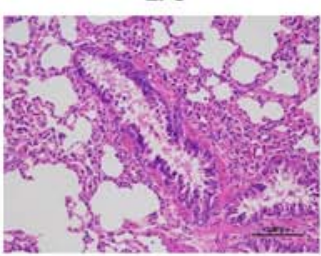

LPS

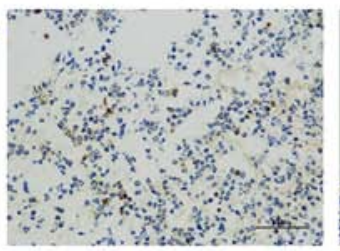

LPS
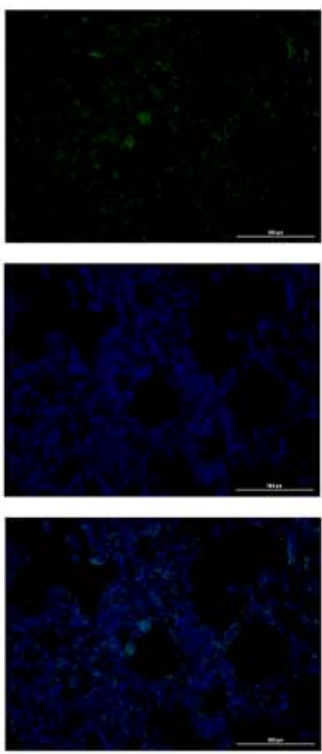

LPS $+0.3 \mathrm{mg} / \mathrm{kg}$ PHC

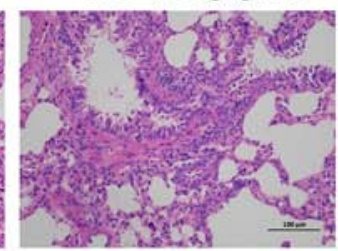

LPS $+0.3 \mathrm{mg} / \mathrm{kg}$ PHC

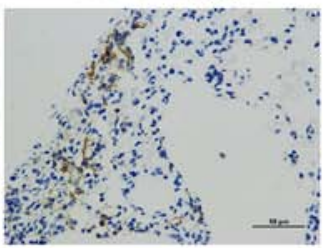

LPS $+0.3 \mathrm{mg} / \mathrm{kg}$ PHC
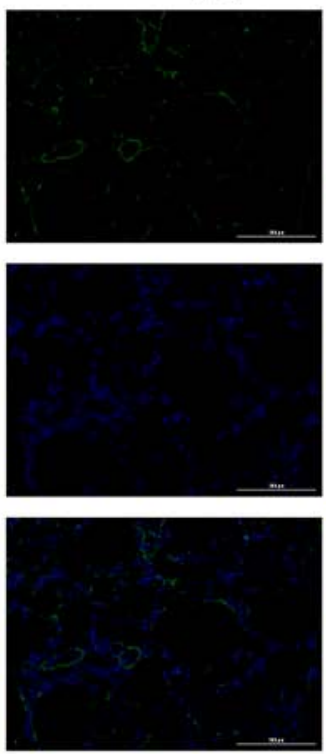

LPS $+1 \mathrm{mg} / \mathrm{kg}$ PHC

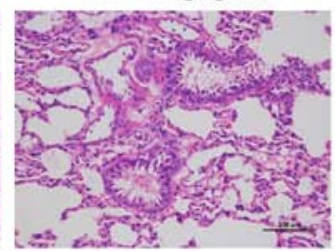

LPS $+1 \mathrm{mg} / \mathrm{kg}$ PHC

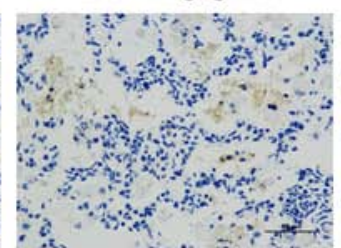

LPS $+1 \mathrm{mg} / \mathrm{kg}$ PHC
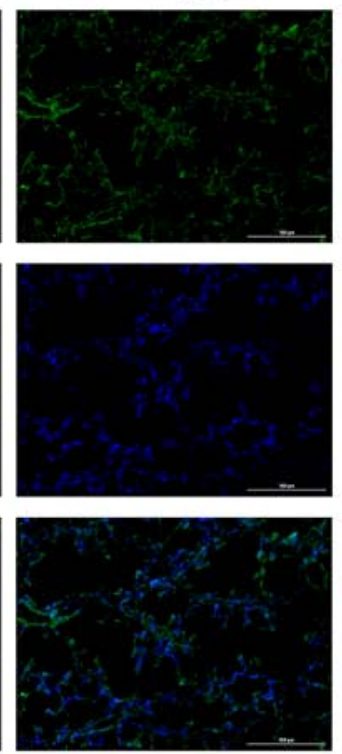

LPS $+3 \mathrm{mg} / \mathrm{kg}$ PHC

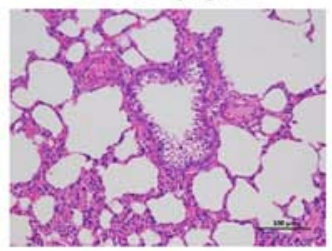

LPS $+3 \mathrm{mg} / \mathrm{kg}$ PHC

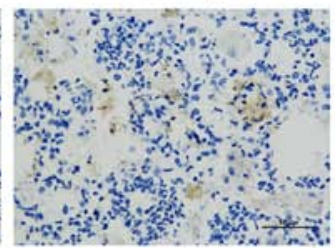

LPS $+3 \mathrm{mg} / \mathrm{kg}$ PHC
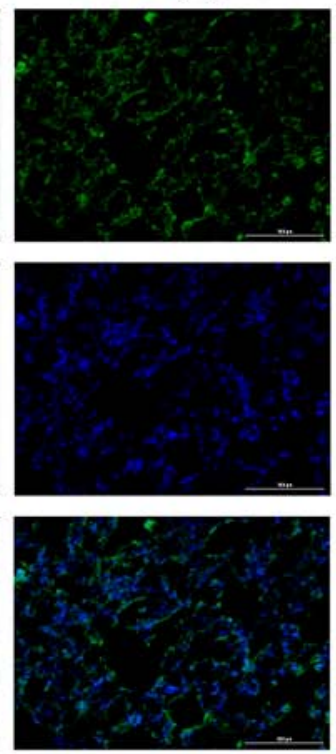

Figure 7. PHC suppresses apoptosis and induces autophagy in a rat model of ALI. The ALI rat model was established by intraperitoneal injection of $5 \mathrm{mg} / \mathrm{kg}$ LPS. ALI model rats were intraperitoneally injected with $0.3,1.0$ or $3.0 \mathrm{mg} / \mathrm{kg}$ PHC $30 \mathrm{~min}$ before LPS injection. (A) Pathological alterations to the lung tissues were assessed by hematoxylin and eosin staining (magnification, x200; scale bar, $100 \mu \mathrm{m}$ ). (B) Cell apoptosis was assessed by conducting TUNEL staining (magnification, $\mathrm{x} 400$; scale bar, $50 \mu \mathrm{m}$ ). (C) The expression of LC3B was confirmed by performing immunofluorescence assays (magnification, x200; scale bar, $100 \mu \mathrm{m})$. PHC, penehyclidine hydrochloride; ALI, acute lung injury; LPS, lipopolysaccharide; LC3, light chain 3.

3-MA reverses the effects of PHC on LPS-induced autophagy in BEAS-2B cells. IF assays and TEM observations were conducted to further investigate the effects of PHC on LPS-induced autophagy in BEAS-2B cells. As demonstrated in Fig. 6A, PHC in combination with 3-MA suppressed the fluorescence intensity of LC3B in LPS-induced BEAS-2B cells compared with PHC treatment alone. In addition, Rapa promoted LPS-induced BEAS-2B cell autophagy. Moreover, the combination of PHC and 3-MA markedly decreased the number of autophagosomes compared with PHC treatment alone (Fig. 6B), which indicated that 3-MA inhibited PHC-mediated autophagy in LPS-induced BEAS-2B cells. Furthermore, Beclin-1 and LC3B expression levels were significantly decreased, whereas p62 expression was significantly increased in the LPS + PHC + 3-MA group compared with the LPS + PHC group. Similarly, Rapa also significantly increased Beclin-1 and LC3B expression levels, but decreased p62 expression levels in LPS-induced BEAS-2B cells compared with the LPS + PHC group, suggesting a crucial role for autophagy (Fig. 6C and D).
PHC suppresses apoptosis and induces autophagy in a rat model of ALI. In addition, in vivo experiments were performed to further investigate the effects of PHC on the morphology, apoptosis and autophagy of lung tissues in ALI model rats. The H\&E staining results demonstrated that the structure of the lung tissues presented as an intact alveolar cavity with no secretions in the alveolar cavity, almost no pulmonary edema and complete alveolar wall structure in the control group. In the model group, the lung tissues displayed a disordered arrangement of alveolar wall cells and a reduced alveolar space accompanied by diffuse hyperemia and small focal pulmonary hemorrhage. In the PHC groups, especially the $3 \mathrm{mg} / \mathrm{kg}$ PHC treatment group, the lung tissues displayed a decrease in the blood-red area on the surface of the lung, and the majority of edema and congestion had disappeared (Fig. 7A). The TUNEL staining results demonstrated that cell apoptosis was markedly enhanced in the LPS group compared with the control group, whereas PHC evidently weakened LPS-induced effects in rats (Fig. 7B). The results from the IF assay revealed that LC3B expression was dramatically downregulated in the LPS 
group compared with the control group, but PHC reversed LPS-induced suppression of LC3B expression in rats (Fig. 7C). Overall, the results demonstrated that PHC inhibited apoptosis and promoted autophagy in ALI model rats.

\section{Discussion}

ARDS is typically characterized by respiratory frequency, distress and progressive hypoxemia, and the clinical mortality rate is $32-55 \%$ worldwide (12). Nonetheless, the mechanism underlying ARDS has yet to be elucidated. ARDS is closely linked to inflammatory reactions and oxidative/antioxidant disorders (29). An increasing number of studies have revealed that apoptosis serves a crucial role in the occurrence and progression of ARDS (30). Apoptosis is an autonomous programmed cell death mediated by multiple genes and is an active process that maintains homeostasis in the body; once the cell apoptosis balance is altered, the individual may experience the development of abnormalities, distortion and even mortality $(31,32)$. Therefore, apoptosis is closely linked to the occurrence of various diseases, such as cancer $(33,34)$, diabetes $(35)$, Parkinson's disease (36) and cardiovascular diseases (37). At present, Bax, Bcl-2 and caspase- 3 have been established to be associated with ARDS (38). ARDS is caused by alveolar-capillary membrane injury triggering pulmonary edema and atelectasis (39). During this process, progressive apoptosis occurs in the alveolar epithelium and pulmonary vascular endothelial cells (40). Bax and Bcl-2 participate in the regulation of apoptosis (41), and caspase-3, a key factor, also participates in the occurrence and development of ARDS $(42,43)$.

$\mathrm{PHC}$ is an anticholinergic drug possessing both antimuscarinic and antinicotinic activities (27). PHC has been ascertained to improve microcirculation, reduce the permeability of capillaries and exert a cell protective effect in ARDS (44). In addition, PHC has been reported to serve an important role as a protective agent for the lungs, wherein PHC preconditioning imparts pulmonary and systemic protection in a rat model of lung ischemia reperfusion injury (18). PHC interaction with the $\mathrm{M}$ receptor diminishes endothelial injury in LPS-stimulated human pulmonary microvascular endothelial cells (45). The protective effect of PHC in rats with myocardial ischemia or reperfusion injury has also been studied $(46,47)$. The present study established an LPS-induced ARDS model. In ARDS model cells, LPS inhibited cell proliferation and promoted apoptosis. Bax and caspase- 3 are proapoptotic proteins, and Bcl-2 is an antiapoptotic protein (48). In the present study, Bax and caspase- 3 were highly expressed in the model group, whereas Bcl-2 displayed significantly decreased expression in the model group compared with the control group. The results indicated that cell apoptosis was induced by LPS. The protective effects of various doses of PHC on the ARDS model regarding cell proliferation and apoptosis were also explored. A dose-dependent study was also conducted, which indicated that cell proliferation was inhibited and cell apoptosis was increased by $\mathrm{PHC}$ in vitro and in vivo in a dose-dependent manner. In addition, higher doses of PHC resulted in more significant reductions in the expression levels of proapoptotic proteins compared with the LPS group.

Inflammatory response to stimulation is a normal response of the body (49). Nevertheless, it can induce the uncontrolled release of inflammatory mediators, such as IFN- $\gamma$, TNF- $\alpha$, IL-1 $\beta$, IL-6 and NO, in severe pathological conditions due to excessive systemic inflammatory response, which can even lead to multiple organ dysfunction syndrome (50). Thus, preventing the overexpression of inflammatory mediators is an effective strategy to prevent ARDS injury. In the present study, PHC significantly reduced the levels of IFN- $\gamma$, TNF- $\alpha$, IL- $1 \beta$, IL-6 and NO in LPS-induced BEAS-2B cells, which indicated that PHC could suppress the inflammatory response of LPS-induced BEAS-2B cells, suggesting that PHC could relieve ARDS injury.

Autophagy is an intracellular chronic mild stress response that involves transportation of damaged proteins to lysosomes for degradation and circulation for maintaining the stability of cell structure, function and metabolism (51). Rapa acts as an autophagy promoter, with the ability to accelerate the formation and maturation of autophagosomes (52); however, 3-MA behaves as an autophagy inhibitor, essentially inhibiting the formation of autophagy bodies (53). In lung diseases, lung tissues frequently display varying degrees of autophagy abnormalities (54) and a moderate degree of autophagy is conducive to the improvement in the disease condition $(55,56)$. Autophagy is closely linked to LPS-induced ALI (57), which can be reversed by Rapa via autophagy promotion (58). A previous study has testified that saturated hydrogen saline improves LPS-induced ALI by regulating autophagy (59). Besides, a previous study has also demonstrated that ethyl pyruvate protects against LPS-induced ALI via regulating autophagy (60). In the present study, the effect of LPS was observed to be associated with cell autophagy. The protective effects of various doses of PHC against cell autophagy in the ARDS model were also explored. p62 expression in the LPS + 3-MA group was the highest among the different groups, but LC3B and Beclin-1 were expressed at the lowest levels in the LPS + 3-MA group among the different groups. By contrast, p62 expression in the LPS + Rapa group was lowest among the different groups, whereas LC3B and Beclin-1 expression levels highest in the LPS + Rapa group compared with the other groups, which indicated that Rapa reversed LPS-induced autophagy. In addition, 3-MA reversed the effects of PHC on LPS-induced proliferation, apoptosis and the inflammatory response in BEAS-2B cells.

PHC evidently facilitated proliferation and autophagy, and suppressed apoptosis and the inflammatory response in LPS-induced BEAS-2B cells and ALI model rats in a dose-dependent manner. In addition, PHC also protected against LPS-induced ARDS injury by influencing the autophagy pathway.

\section{Acknowledgements}

Not applicable.

\section{Funding}

No funding was received.

\section{Availability of data and materials}

The datasets used and/or analyzed during the current study are available from the corresponding author on reasonable request. 


\section{Authors' contributions}

XW participated in designing the study and performing the experiments. FL and MX helped perform the experiments and analyze the data. XW and LW wrote the manuscript and analyzed data. All authors read and approved the final manuscript.

\section{Ethics approval and consent to participate}

The present study was approved by the Ethics Committee of the Shanghai Jiaotong University Affiliated Sixth People's Hospital.

\section{Patient consent for publication}

Not applicable.

\section{Competing interests}

The authors declare that they have no competing interests.

\section{References}

1. Matthay MA and Zemans RL: The acute respiratory distress syndrome: Pathogenesis and treatment. Annu Rev Pathol 6: 147-163, 2011.

2. Li BQ, Sun HC, Nie SN, Shao DB, Liu HM and Qian XM: Effect of penehyclidine hydrochloride on patients with acute lung injury and its mechanisms. Chin J Traumatol 13: 329-335, 2010.

3. Saguil A and Fargo M: Acute respiratory distress syndrome: Diagnosis and management. Am Fam Physician 85: 352-358, 2012 .

4. Lee-Chiong T Jr and Matthay RA: Drug-induced pulmonary edema and acute respiratory distress syndrome. Clin Chest Med 25: 95-104, 2004.

5. Shah J and Rana SS: Acute respiratory distress syndrome in acute pancreatitis. Indian J Gastroenterol 39: 123-132, 2020.

6. Ibadov RA, Arifjanov AS, Ibragimov SK and Abdullajanov BR: Acute respiratory distress-syndrome in the general complications of severe acute pancreatitis. Ann Hepatobiliary Pancreat Surg 23: 359-364, 2019.

7. Iriyama $\mathrm{H}$, Abe $\mathrm{T}$, Kushimoto $\mathrm{S}$, Fujishima $\mathrm{S}$, Ogura $\mathrm{H}$, Shiraishi A, Saitoh D, Mayumi T, Naito T, Komori A, et al: Risk modifiers of acute respiratory distress syndrome in patients with non-pulmonary sepsis: A retrospective analysis of the FORECAST study. J Intensive Care 8: 7, 2020

8. Rambaud J, Lidouren F, Sage M, Kohlhauer M, Nadeau M, Fortin-Pellerin É, Micheau P, Zilberstein L, Mongardon N, Ricard JD, et al: Hypothermic total liquid ventilation after experimental aspiration-associated acute respiratory distress syndrome. Ann Intensive Care 8: 57, 2018.

9. Tambe A, Gentile T, Ramadas P, Tambe V and Badrinath M: Cytomegalovirus pneumonia causing acute respiratory distress syndrome after brentuximab vedotin therapy. Am J Ther 26: e794-e795, 2019.

10. Killien EY, Huijsmans RLN, Ticknor IL, Smith LS, Vavilala MS, Rivara FP and Watson RS: Acute respiratory distress syndrome following pediatric trauma: Application of pediatric acute lung injury consensus conference criteria. Crit Care Med 48: e26-e33, 2020.

11. Fan E, Brodie D and Slutsky AS: Acute respiratory distress syndrome: Advances in diagnosis and treatment. JAMA 319: 698-710, 2018

12. Fanelli V and Ranieri VM: Mechanisms and clinical consequences of acute lung injury. Ann Am Thorac Soc 12 (Suppl 1): S3-S8, 2015.

13. Su BC, Huang HN, Lin TW, Hsiao CD and Chen JY: Epinecidin-1 protects mice from LPS-induced endotoxemia and cecal ligation and puncture-induced polymicrobial sepsis. Biochim Biophys Acta Mol Basis Dis 1863: 3028-3037, 2017.
14. Chen M, Chen C, Yuan X, Chen X, Zheng F, Shao L and Zhang Z: Angiotensin II aggravates lipopolysaccharide induced human pulmonary microvascular endothelial cells permeability in high glucose status. Endocr J 65: 717-725, 2018.

15. Wang H, Wang T, Yuan Z, Cao Y, Zhou Y, He J, Shen Y, Zeng N, Dai L, Wen F and Chen L: Role of receptor for advanced glycation end products in regulating lung fluid balance in lipopolysaccharide-induced acute lung injury and infection-related acute respiratory distress syndrome. Shock 50: 472-482, 2018.

16. Wu DQ, Wu HB, Zhang M and Wang JA: Effects of zinc finger protein A20 on lipopolysaccharide (LPS)-induced pulmonary inflammation/anti-inflammatory mediators in an acute lung injury/acute respiratory distress syndrome rat model. Med Sci Monit 23: 3536-3545, 2017.

17. Shi L, Dong N, Ji D, Huang X, Ying Z, Wang X and Chen C: Lipopolysaccharide-induced $\mathrm{CCN} 1$ production enhances interleukin-6 secretion in bronchial epithelial cells. Cell Biol Toxicol 34: 39-49, 2018.

18. Wang Y, Lin D, Tan H, Gao Y and Ma J: Penehyclidine hydrochloride preconditioning provides pulmonary and systemic protection in a rat model of lung ischaemia reperfusion injury. Eur J Pharmacol 839: 1-11, 2018.

19. Xiao HT, Liao Z and Tong RS: Penehyclidine hydrochloride: A potential drug for treating COPD by attenuating Toll-like receptors. Drug Des Devel Ther 6: 317-22, 2012.

20. Wang Y, Gao Y and Ma J: Pleiotropic effects and pharmacological properties of penehyclidine hydrochloride. Drug Des Devel Ther 12: 3289-3299, 2018.

21. Lin D, Ma J, Xue Y and Wang Z: Penehyclidine hydrochloride preconditioning provides cardioprotection in a rat model of myocardial ischemia/reperfusion injury. PLoS One 10: e0138051, 2015.

22. Shen W, Gan J, Xu S, Jiang G and Wu H: Penehyclidine hydrochloride attenuates LPS-induced acute lung injury involvement of NF-kappaB pathway. Pharmacol Res 60: 296-302, 2009.

23. Wang YA, Zhou WX, Li JX, Liu YQ, Yue YJ, Zheng JQ, Liu KL and Ruan JX: Anticonvulsant effects of phencynonate hydrochloride and other anticholinergic drugs in soman poisoning: neurochemical mechanisms. Life Sci 78: 210-223, 2005.

24. Guoshou Z, Chengye Z, Zhihui L and Jinlong L: Effects of high dose of anisodamine on the respiratory function of patients with traumatic acute lung injury. Cell Biochem Biophys 66: 365-369, 2013.

25. Zhan J, Xiao F, Li JJ, Zhang ZZ, Chen K, Wang YP and Wang YL: Penehyclidine hydrochloride decreases pulmonary microvascular permeability by upregulating beta arrestins in a murine cecal ligation and puncture model. J Surg Res 193: 391-398, 2015.

26. Krenn K, Lucas R, Croizé A, Boehme S, Klein KU, Hermann R, Markstaller K and Ullrich R: Inhaled AP301 for treatment of pulmonary edema in mechanically ventilated patients with acute respiratory distress syndrome: A phase IIa randomized placebo-controlled trial 21: 194, 2017.

27. Zheng F, Xiao F, Yuan QH, Liu QS, Zhang ZZ, Wang YL and Zhan J: Penehyclidine hydrochloride decreases pulmonary microvascular endothelial inflammatory injury through a beta-arrestin-1-dependent mechanism. Inflammation 41: 1610-1620, 2018

28. Dong L, Yu WM, Zheng H, Loh ML, Bunting ST, Pauly M, Huang G, Zhou M, Broxmeyer HE, Scadden DT and Qu CK: Leukaemogenic effects of Ptpn11 activating mutations in the stem cell microenvironment. Nature 539: 304-308, 2016.

29. Huang, X, Kong G, Li Y, Zhu W, Xu H, Zhang X, Li J, Wang L, Zhang $\mathrm{Z}$ et al., Decitabine and 5-azacitidine both alleviate LPS induced ARDS through anti-inflammatory/antioxidant activity and protection of glycocalyx and inhibition of MAPK pathways in mice. Biomedicine \& Pharmacotherapy 84: 447-453, 2016.

30. Kellner M., Noonepalle S., Lu Q., Srivastava A., Zemskov E., Black S.M: ROS Signaling in the Pathogenesis of Acute Lung Injury (ALI) and Acute Respiratory Distress Syndrome (ARDS). In: Wang YX. (eds) Pulmonary Vasculature Redox Signaling in Health and Disease. Advances in Experimental Medicine and Biology. Springer, Cham 967. pp105-137, 2017

31. Kartlaşmış K, Kökbaş U and Kayrin L: Biochemistry of apoptosis. Arch Med Rev J 25: 52-69, 2016.

32. Redza-Dutordoir M and Averill-Bates DA: Activation of apoptosis signalling pathways by reactive oxygen species. Biochim Biophys Acta 1863: 2977-2992, 2016.

33. Ekizceli G, Uluer ET and Inan S: Investigation of the effects of rapamycin on the mTOR pathway and apoptosis in metastatic and non-metastatic human breast cancer cell lines. Bratisl Lek Listy 121: 308-315, 2020. 
34. Diwanji $\mathrm{N}$ and Bergmann A: An unexpected friend-ROS in apoptosis-induced compensatory proliferation: Implications for regeneration and cancer. Semin Cell Dev Biol 80: 74-82, 2018.

35. El-Shafey ES and Elsherbiny ES: The role of apoptosis and autophagy in the insulin-enhancing activity of oxovanadium(IV) bipyridine complex in streptozotocin-induced diabetic mice. Biometals 33: 123-135, 2020.

36. Liu J, Liu W and Yang H: Balancing apoptosis and autophagy for parkinson's disease therapy: Targeting BCL-2. ACS Chem Neurosci 10: 792-802, 2019.

37. Yang Y, Gao H, Zhou H, Liu Q, Qi Z, Zhang Y and Zhang J: The role of mitochondria-derived peptides in cardiovascular disease: Recent updates. Biomed Pharmacother 117: 109075, 2019.

38. Kiraz Y, Adan A, Kartal Yandim M and Baran Y: Major apoptotic mechanisms and genes involved in apoptosis. Tumour Biol 37 8471-8486, 2016.

39. Wang J, Oppenheimer L, Fata P, Pintin J, Stimpson R and Mantsch HH: Spectroscopic approach to capillary-alveolar membrane damage induced acute lung injury. Can Respir J 6 : 499-506, 1999

40. Kiser TH, Burnham EL, Clark B, Ho PM, Allen RR, Moss M and Vandivier RW: Half-dose versus full-dose alteplase for treatment of pulmonary embolism. Crit Care Med 46: 1617-1625, 2018.

41. Li W, Qiu X, Jiang H, Han Y, Wei D and Liu J: Downregulation of miR-181a protects mice from LPS-induced acute lung injury by targeting $\mathrm{Bcl}-2$. Biomed Pharmacother 84: 1375-1382, 2016.

42. Li B, Zeng M, Zheng H, Huang C, He W, Lu G, Li X, Chen Y and Xie R: Effects of ghrelin on the apoptosis of human neutrophils in vitro. Int J Mol Med 38: 794-802, 2016.

43. Wang L, Wang T, Li H, Liu Q, Zhang Z, Xie W, Feng Y, Socorburam T,WuG, XiaZ and WuQ: Receptorinteracting protein 3 -mediated necroptosis promotes lipopolysaccharide-induced inflammation and acute respiratory distress syndrome in mice. PLoS One 11: e0155723, 2016.

44. Zhan J, Wang Y, Wang C, Li J, Zhang Z and Jia B: Protective effects of penehyclidine hydrochloride on septic mice and its mechanism. Shock 28: 727-732, 2007.

45. Yuan Q, Xiao F, Liu Q, Zheng F, Shen S, He Q, Chen K, Wang Y, Zhang $Z$ and Zhan $\mathrm{J}: \mathrm{M}_{3}$ receptor is involved in the effect of penehyclidine hydrochloride reduced endothelial injury in LPS-stimulated human pulmonary microvascular endothelial cell. Pulm Pharmacol Ther 48: 144-150, 2018.

46. Feng M, Wang L, Chang S and Yuan P: Penehyclidine hydrochloride regulates mitochondrial dynamics and apoptosis through p38MAPK and JNK signal pathways and provides cardioprotection in rats with myocardial ischemia-reperfusion injury. Eur J Pharm Sci 121: 243-250, 2018.

47. Lin D, Cui B, Ren J and Ma J: Regulation of VDAC1 contributes to the cardioprotective effects of penehyclidine hydrochloride during myocardial ischemia/reperfusion. Exp Cell Res 367: 257-263, 2018.
48. Liu ZY, Guo L, Xiao G, Dong GY, Zhang YX, Cheng H, Wang XY and Yang C: Significance and expression of c-erBb-2, p53, and caspase-3 in breast cancer tissue in different age groups. Eur J Gynaecol Oncol 39: 430-432, 2018.

49. Bosmann $\mathrm{M}$ and Ward PA: The inflammatory response in sepsis. Trends Immunol 34: 129-236, 2013.

50. Johnson CL, Soeder Y and Dahlke MH: Concise review: Mesenchymal stromal cell-based approaches for the treatment of acute respiratory distress and sepssis syndromes. Stem Cells Transl Med 6: 1141-1151, 2017.

51. Monteleon CL, Agnihotri T, Dahal A, Liu M, Rebecca VW, Beatty GL, Amaravadi RK and Ridky TW: Lysosomes support the degradation, signaling, and mitochondrial metabolism necessary for human epidermal differentiation. J Invest Dermatol 138 1945-1954, 2018.

52. Ko S, Gu MJ, Kim CG, Kye YC, Lim Y, Lee JE, Park BC, Chu H, $\mathrm{Han} \mathrm{SH}$ and Yun CH: Rapamycin-induced autophagy restricts porcine epidemic diarrhea virus infectivity in porcine intestinal epithelial cells. Antiviral Res 146: 86-95, 2017.

53. Lv C, Wang L, Zhu X, Lin W, Chen X, Huang Z, Huang L and Yang S: Glucosamine promotes osteoblast proliferation by modulating autophagy via the mammalian target of rapamycin pathway 99: 271-277, 2018.

54. Zeng M, Sang W, Chen S, Chen R, Zhang H, Xue F, Li Z, Liu Y, Gong Y: 4-PBA inhibits LPS-induced inflammation through regulating ER stress and autophagy in acute lung injury models. Toxicol 271 (5): 26-37, 2017.

55. Ren J and Zhang Y: Targeting autophagy in aging and aging-related cardiovascular diseases. Trends Pharmacol Sci 39: 1064-1076, 2018.

56. Decuypere JP, Ceulemans LJ, Agostinis P, Monbaliu D, Naesens M,Pirenne J and Jochmans I: Autophagy and the kidney: Implications for ischemia-reperfusion injury and therapy. Am J Kidney Dis 66: 699-709, 2015.

57. Gao Y, Wang N, Liu L, Liu Y and Zhang J: Relationship between mammalian target of rapamycin and autophagy in lipopolysaccharide-induced lung injury. J Surg Res 201: 356-363, 2016.

58. Zhao H and Luo F: Rapamycin reverse lipopolysaccharideinduced acute lung injury through activating autophagy flux. J Pharm Univ, 2015.

59. Liu Y and Zhang J: Saturated hydrogen saline ameliorates lipopolysaccharide-induced acute lung injury by reducing excessive autophagy. Exp Ther Med 13: 2609-2615, 2017.

60. Zhu Q, Wang H, Wang H, Luo Y, Yu Y, Du Q, Fei A and Pan S: Protective effects of ethyl pyruvate on lipopolysaccharide-induced acute lung injury through inhibition of autophagy in neutrophils. Mol Med Rep 15: 1272-1278, 2017.

This work is licensed under a Creative Commons

Attribution-NonCommercial-NoDerivatives 4.0 International (CC BY-NC-ND 4.0) License. 